\title{
TERAPI PASIR PANAS (TAPA SVEDA) UNTUK KESEHATAN PERSPEKTIF AYURWEDA
}

\author{
Ida Bagus Putra Suta \\ Program Studi Kesehatan Ayurweda, Fakultas Kesehatan \\ Universitas Hindu Indonesia Denpasar \\ E-mail: putrasutakaleran@gmail.com
}

\begin{abstract}
Absrak
Hidup sehat dan umur panjang adalah sebuah harapan dan dambaan semua orang, sebagaimana yang diajarkan dalam Ayurweda, namun untuk menjaga agar tubuh tetap sehat sering kali dilupakan banyak orang, sehingga menimbulkan gangguan kesehatan atau penyakit.Untuk mengembalikan kesehatannya maka akan dilakukan pengobatan atau terapi, di dalam Ayurweda disebut dengan Chikitsa. Sebuah fenomena tentang terapi untuk kesehatan banyak kita jumpai dalam kehidupan masyarakat kita. Salah satu dari berbagai metoda terapi tersebut adalah terapi menggunakan pasir panas (Tapa Sweda). Fenomena tersebut dijadikan objek penelitian dengan judul penelitian: Terapi Pasir Panas(Tapa Sveda) Untuk Kesehatan Perspektif Ayurweda. Penelitian ini menggunakan metode kwalitatif, dengan pendekatan Ayurweda. Ayurweda dipakai sebagai pendekatan karena usada Bali memiliki prinsip dasar pengobatan yang sama dengan Ayurweda yaitu dengan bahan alam. Dari hasil pembahasan terhadap rumusan masalah maka didapat simpulan bahwaTapa Sveda adalah sebuah terapi dengan menggunakan media pasir panas sebagai sebuah terapi berkeringat (Svedacaraniya cikitsita) yang bertujuan mengeluarkan ama (racun tubuh). Terapi pasir panas(Tapa sweda)dapat mengatasi beberapa penyakit, khususnya penyakit yang disebabkan oleh unsur vata dan kapha, yaitu penyakit yang disebut Ama Vata atau rematik akut.
\end{abstract}

Kata Kunci: Ayurweda, Chikitsa, Svedacaraniya, Terapi PasirPanas dan Ama Vata

Abstract

Healthy life and longevity are all hopes and desires of all people, as taught in Ayurvedic, but to keep the body healthy, often forgotten by many people, causing health problems or diseases. To restore health, treatment or therapy will be carried out, in Ayurveda called Chikitsa. A phenomenon about therapy for health we encounter in many of our lives. One of the various therapeutic methods is therapy using hot sand (Tapa Sweda). This phenomenon is used as the object of research with the research title: Heat Sand Therapy (Tapa Sveda) for Ayurvedic Perspective Health. This research uses qualitative methods, with Ayurvedic approach. Ayurvedic is used as an approach because usada Bali has the same basic principles of treatment as Ayurvedic, namely natural ingredients. From the results of the discussion on the formulation of the problem, the conclusion is that Tapa Sveda is a therapy using hot sand as a therapy for sweating (Svedacaraniya Cikitsita) which aims to remove the body poison. Hot sand therapy (Tapa sweda) can overcome several diseases, especially diseases caused by vata and kapha, a disease called Ama Vata or acute rheumatism.

Key Word: Ayurweda, Chikitsa, Svedacaraniya, Hot Sand Therapy and Ama Vata

\section{Pendahuluan}

Hidup sehat dan umur panjang adalah sebuah harapan dan dambaan semua orang, sebagaimana yang diajarkan dalam Ayurweda, namun untuk menjaga agar tubuh tetap sehat sering kali dilupakan banyak orang, sehingga menimbulkan gangguan kesehatan atau penyakit. Bila kesehatan sudah terganggu maka akandiupayakan suatu usaha mengembalikan kesehatannya, baik dengan obat maupun 
dengan metode-metode yang lain. Ada yang menggunakan tanaman sebagai bahan obat, ada yang menggunakan binatang dan ada juga yang menggunakan unsur Panca Maha Bhuta dan juga upaya spiritual.

Ayurveda didasarkan pada falsafah Samkhya atau falsafah penciptaan, yang mana dalam falsafah Samkhya muncul prinsip yang membentuk jagad raya ini adalah: ether, udara, api, air dan tanah/bumi. Ini adalah unsur-unsur dari lingkungan dan dari diri kita sendiri (Murray, Pickup : 1320). Hal senada juga dipaparkan oleh Nala, (2001:113) yang menyatakan bahwa Manusia disebut pula sebagai bhuana alit atau mikrokosmos, merupakan bagian yang tidak terpisahkan dengan bhuana agung atau makrokosmos (alam semesta). Oleh sebab itu, unsur-unsur yang menyusun tubuh manusia sebagai bhuana alit adalah sama dengan unsur-unsur yang menyusun alam raya atau bhuana agung. Sebagai diketahui, unsur tersebut terdiri atas limabhuta yang disebut panca mahabhuta. Kelima bhuta tersebut adalah: akasa, vayu, teja apah, dan prthvi

Nala (2001:75) menjelaskan bahwa svasthya atau sehat menurut Ayurweda adalah: seseorang yang memilki keseimbangan dalam dosha dan agni (enzim pencernaan dan metabolisme) dimana dhatu (jaringan tubuh) berfungsi dengan baik, serta mala (limbah,ekskreta) dibuang secara teratur dan mempunyai kebahagiaan atma (spirit), indriya, dan manah (pikiran).

Chikitsa, adalah suatu tindakan pengobatan, terapi atau penyembuhan untuk mengembalikan keadaan tidak seimbang dari unsur tri dosha (vatta, pitta dan kapha) di dalam tubuh.Prinsip chikitsaatau pengobatan dalam Ayurweda adalah secara tidak langsung mencegah perkembangan vyadi, roga, abadha atau penyakit yang ada di dalam tubuh manusia (Nala, 2001 : 79).

Dalam kitab Ayurweda, ada lima cara untuk mengembalikan keseimbangan ketiga unsurtri-dosha yang terganggu, yang disebut dengan Panca Karma, berupa: pijat (pemijatan dengan ramuan obat atau tanpa obat), sauna (mandi uap, dengan air panas), perspirasi (mengeluarkan keringat, baik dengan ramuan obat maupun dengan cara fisik dan pergerakan otot), diaresis (mengeluarkan air kencing sebanyak mungkin dengan ramuan obat), dan diet (mengatur makanan dan minuman, termasuk pantangan) (Nala,1992:35).
Fenomena upaya penanganan atau suatu usaha untuk memperoleh kesehatannya kembali yang telah dilakukan oleh para pangusada (pengobat) atau dilakukan sendiri oleh mereka ,dengan cara berjemur di bawah matahari pagi dan membalur tubuh dengan pasir laut yang panas, dan bila dilihat dari cara Ayurweda termasuk pada terapi menggunakan pasir panas disebut dengan Tapa Sveda.

Bukan suatu kebetulan apa yang telah dilakukan dengan metode terapi yang dilakukan, tetapi Tapa Svedaini banyak dilakukan oleh mereka yang rata-rata berusia tua, walaupun ada yang berusia remaja bahkan anak-anak, dan kebanyakan dari mereka memang terlihat bermasalah dengan kondisi kesehatan mereka. Dari apa yang telah mereka lakukan muncul suatu pertanyaan cara terapi apakah yang merka lakukan? Penyakit apa saja yang bisa mereka bisa atasi dengan cara tersebut?

\section{Kajian Pustaka}

Rhyner (198) dalam bukunya berjudul Ayurveda The Gentle Health System ada memaparkan tentang terapi berkeringat (Svedakarma), yang mana dijelaskan bahwa keringat (sveda) adalah suatu produk buangan dari tubuh yang sangat perlu dipertimbangkan keberadaannya, karena jika produk buangan (ama) tersebut tidak keluar maka itu akan menyebabkan sakit. Terapi berkeringat (svedakarma) ini sangat baik untuk mengurangi vata dan kapha. Kontra indikasi dari terapi berkeringat ini adalah bagi penderita hepatitis, diabetes, muntahmuntah, luka bakar, keracunan dan diare.Secara umum, Ayurveda mebedakan antara dua perbedaan dari tipe terapi berkeringat (svedakarma). Tipe pertama adalah dengan menggunakan panas (agni) dan yng ke dua adalah dengan aktivias fisik seperti olah raga. Ahli dari Kerala membedakan antara empat perberdaan metode yaitu: thapam, upanaha, ushma dan drava. PerlakuanThapasvedatersebut adalahdenganmenggunakan kabut tipis, handuk, selimut, dan yang sejenis itu yang panas dan diletakkan pada bagian tubuh tertentu.

Mahadevan, 2012, dalam bukunya Ayurveda For Beginners ada menyebutkan Sveda Vidhi (Sudation) sebagai sebuah metoda pengobatan berkeringat yang bermanfaat untuk mengatasi penyakit yang 
disebabkan oleh produk buangan (mala) dalam tubuh. Tentang Tapa Sveda juga dijelaskan sebagai bagian dari tipe pengobatan berkeringat (Svedana) yang terapinya menggunakan benda-benda yang dipanaskan.

Babu, 2010, dalam bukunya berjudul The Principles and Practice Of Kaya Cikitsa (Ayurveda's Internal Medicine), juga ada menyebutkan tentang manfaat terapi berkeringat atau Svedana, khususnya tipe Tapa Sveda untuk mengatasi penyakit karena Vata dan Kapha.

Murthy, 2010, di dalam bukunya yang berjudul Illustrated Susruta Samhita ada menjelaskan tentang penggunaan pasir panas sebagai sebuah metode pengobatan yang merupakan salah satu tipe dari Svedacaraniya cikitsita yang disebut dengan pengobatan Tapa Sveda.

\section{Metode Penelitian}

Jenis penelitian yang dilakukan ini adalah difokuskan ke dalam penelitian kwalitatif yang menggunakan pendekatan Ayurweda.Ayurweda dipakai sebagai sebuah pendekatan karena Ayurweda merupakan pengetahuan tentang hidup sehat dan umur panjang. Di dalam Ayurweda dikenal banyak metode terapi dan juga dikenal penggunaan bahan-bahan natural (unsur Panca Mahabutha) sebagai sarana pengobatan.

Data yang dicari pada penelitian ini adalah bersifat kwalitatif, yaitu prosedur ilmiah yang menghasilkan data deskriptif berupa kata-kata tertulis atau lisan dari orang-orang dan perilaku yang dapat diamati.

Sumber data yang didapat pada penelitian adalah dari informan langsung di lapangan yang didapat dari hasil wawancara, dan data tersebut akan dijadikan sebagai data primer, sedangakan data sekunder akan didapat dari pustaka-pustaka yang menjadi acuan di dalam penelitian ini. Teknik pengambilan datanya adalah dengan purposive sampling.Di dalam pengambilan data sudah pasti dilengkapi dengan beberapa instrument pendukung dari instrument kuncinya.

Penelitian ini dilakukan dengan melakukan prosedur sebagai berikut: 1 . Observasi, 2. Wawancara mendalam, 3. Studi Kepustakaan. Setelah semua data didapat, akan dilakukan analisis data dengan tiga tahap, yaitu reduksi data, penyajian data, dan verifikasi atau simpulan

\section{Pembahasan}

a. Terapi dengan Pasir Panas sebagai Tapa Sweda.

Terlepas dari ajaran Ayurweda secara utuh yang berkembang di India, di Bali juga berkembang sistem pengobatan yang dikenal dengan Usada.Banyak metoda pengobatan yang diterapkan di Bali mempunyai kemiripan yang dijelaskan di dalam sistem pengobatan Ayurweda, seperti halnya tradisi yang dilakukan oleh masyarakat Bali dengan melakukan terapi dengan berjemur dan membalur diri dengan pasir panas yang menjadi objek penelitian ini. Ayurweda menyatakan bahwa bila dapat mengembalikan keseimbangan dari tri dhosa yang terganggu maka orang yang sakit (roga, duhkha, asvasthya) akan menjadi sembuh (svasthya, arogya).

Ayurweda juga menginspirasikan bermunculannya sistem-sistem pengobatan tradisional lain seperti naturopathy, obatobatan Tibetan, Buddhis, dan Unani-tibb (pengobatan model Yunani-Arab), karena secara teori dan praktek ada banyak kesamaan diantara mereka (Dash \& Ramaswamy, 2006 : 2).

Chikitsa, adalah suatu tindakan pengobatan, terapi atau penyembuhan untuk mengembalikan keadaan tidak seimbang dari unsur tri dosha (vatta, pitta dan kapha) di dalam tubuh.Prinsip chikitsaatau pengobatan dalam Ayurwea adalah secara tidak langsung mencegah perkembangan vyadi, roga, abadha atau penyakit yang ada di dalam tubuh manusia (Nala, 2001 : 79).

Anonim, (2012:--) menyatakan bahwa Panchakarma berasal dari bahasa Sansekerta yang artinya "lima tindakan" atau "lima perawatan."Panchakarma merupakan proses yang digunakan untuk membersihkan tubuh dari bahan-bahan beracun yang berasal dari penyakit dan makanan yang buruk.Ayurweda mengatakan bahwa dosha yang tidak seimbang akan menimbulkan sampah dalam tubuh.Dalam Ayurweda, sampah disebut sebagai Ama. Ama adalah sesuatu yang berbau busuk, lengket, atau zat beracun yang harus dibuang dari badan sesegara mungkin.Panchakarmaakan mengeluarkan kelebihan atau ketidakseimbangan dosha bersama dengan Ama yang menempel, keluar melalui sistem pengeluaran tubuh 
seperti kelenjar keringat, saluran kencing, usus, dan lain-lain.

Tapa Sveda adalah sebuah metode terapi dengan menggunakan pasir panas, yang diterapkan pada penderita Ama vata (reumatik akut) (Babu, 2010:38).Pendapat yang sama juga ada menyatakan bahwa Tapa sveda dilakukan dengan menggunakan tangan (telapak tangan) lembaran perunggu, bola (dari lumpur, logam dll) pot sherds, pasir dan kain (semua ini dibuat panas oleh api sebelumnya dan diterapkan pada tubuh). Sudasi tubuh orang yang berbaring telentang biasanya dilakukan dengan menggunakan batu bara dari kayu khadira (Murthy, 2010:300)

Tapa Svedamerupakan bagian dari terapi yang disebut Sveda Vidhi.Sveda berarti keringat yang merupakan mala yang dihilangkan melalui Pitta panas).Terapi

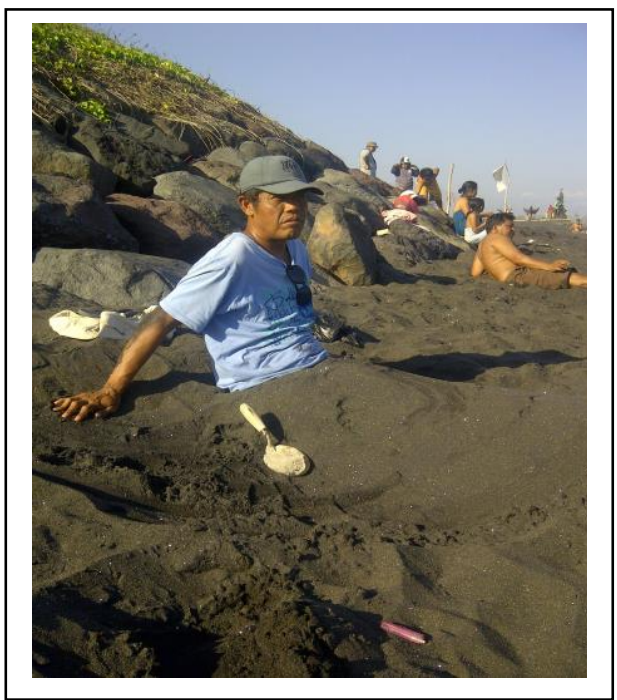

Gambar 1. Membenam lutut dengan pasir panas

Dari hasil observasi dan wawancara yang didapat di lapangan, bahwa mereka yang melakukan terapi dengan pasir panas adalah telah melakukan suatu metode chikitsa atau terapi, yang mana.mereka telah memperlakukan dirinya dengan cara berjemur di bawah sinar matahari di hamparan pasir pantai dan membalur bahkan ada yang membenamkan tubuh mereka dengan pasir lautyang panas atau hangat karena paparan matahari yang menyinari hamparan pasir tersebut dari pagi hari, dengan harapan kesehatan mereka kembali didapat, atau yang membantu dalam memproduksi keringat disebut svedana.Dalam svedana, prosdur tertentu dilakukan untuk melebarkan srota (pembuluh) dan membantu tubuh berkeringat. Ini dilakukan setelah terapi sneha (peminyakan) untuk memfasilitasi menghilangkan ama (racun tubuh) dan mala (sisa produksi metabolisme tubuh) dari srota (pembuluh) dan dathu (jaringan) dan untuk mengangkut mereka kembali ke kostha (saluran pencernaan) (Mahadevan, 2012:73) dan pendapat ini senada dengan pendapat Rhyner (1998: 127-128)

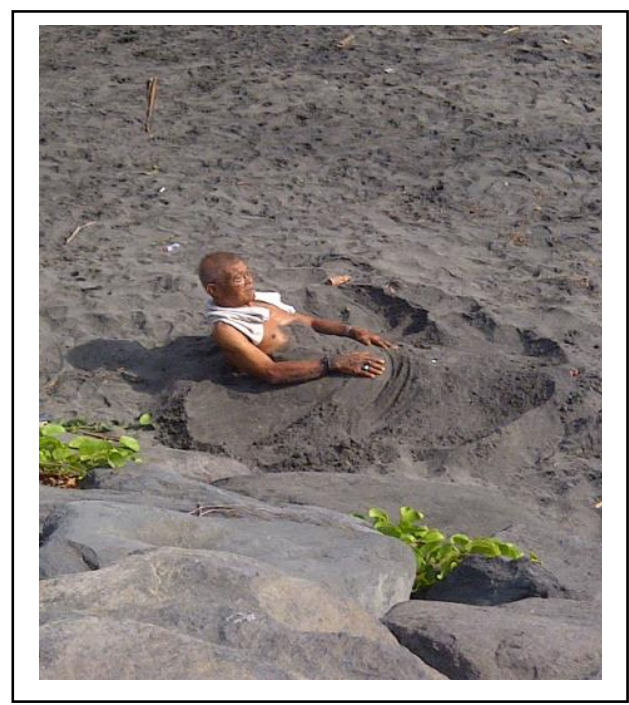

Gambar 2. Membenam pinggang hingga lutut dengan pasir panas

keluhan sakit yang mereka derita bisa hilang. Tanpa mereka sadari bahwa apa yang mereka lakukan adalah merupakan sebuah perlakuan terapi yang di dalam ayurweda disebut Svedana Karma(perlakuan terapi berkeringat), dengan tipe khusus yang disebut dengan Tapa Sveda, yaitu suatu terapi dengan berkeringat dengan salah satunya menggunakan pasir panas. (Gambar :1 dan Gambar : 2)

\section{b. Penyakit Yang Dapat Diatasi Dengan Terapi Pasir Panas (Tapa Sveda).}


Sebagaimana telah dijelaskan bahwa penyakit bisa terjadi karena unsur tri dosha di dalam tubuh tidak seimbang, enzim (agni) dan jaringan tubuh (dathu) di dalam tubuh tidak seimbang, dibarengi dengan ekskresi (mala) tidak berkerja dengan baik. Untuk dapat mengembalikan dan memperbaikinya, maka salah satu upaya yang dapat dilakukan adalah dengan cikitsa (terapi).Salah satu terapi yang dilakukan untuk mengatasi keluhan penyakit itu adalah dengan terapi menggunakan media pasir panas atau istilah dalam Ayurwedanya adalah Tapa Sveda.

Hasil data yang didapat menunjukkan bahwa, sebagaian besar dari responden menyatakan mereka melakukan terapi pasir panas karena ada keluhan pada organ tungkai mereka, khususnya daerah persendian, ada yang menyatakan terserang reumatik, asam urat dan sisanya lagi dari keluhannyeri sendi, walaupun ada beberapa menyatakan keluhan yang lain. Dari hasil wawancara dengan responden, semua responden menyatakan ada perubahan lebih baik pada diri mereka setelah melakukan terapi pasir panas(Tapa Sveda) walupun tidak semuabisa sembuh total, tetapi ada perubahan ke arah lebih baik.

Dari sekian jenis penyakit yang mendapat perlakuan terapi dengan Tapa Sveda, untuk penderita rematik, asam urat, dan persendian kaku berpotensi kembali baik atau mendapat kesembuhan dalam waktu yang relative cepat.

Sebagaimana telah dijelaskan bahwa terapi Sveda Karma sangat efektiv untuk mengatasi penyakit karena unsur Vata dan Kapha, walaupun ada beberapa jenis penyakit yang tidak boleh mendapat perlakuan terapi ini. Cara kerja dari terapi Svedana, yaitu dengan mengeluarkan ama (racun tubuh) melalui keringat, sehingga terapi dengan menggunakan pasir panas yang bertujuan dapat memberikan efek berkeringat, sehingga akan lebih efektif dalam mengatasi penyakit ama vata (reumatik akut)

\section{Simpulan dan Saran \\ a. Simpulan.}

Dari hasil pembahasan terhadap rumusan masalah maka dapat disimpulkan bahwaTapa sveda adalah sebuah terapi dengan menggunakan pasir panas yang menempel pada bagian tubuh yang menyebabkan tubuh berkeringat untuk membantu keluarnya ama atau racun tubuh sehingga produk buangan dari tubuh tidak menumpuk di dalam tubuh itu sendiri.
Terapi pasir panas atau Tapa Svedasangat efektiv untuk mengatasi penyakit, khususnya penyakit yang berhubungan dengan metabolisme tubuh dan darahkhususnya yang berkaitan dengan ama dan mala, sehingga sangat efektiv untuk penyakit karena Vata dan Kaphaseperti penyakit Ama Vata atau reumatik akut.

\section{b. Saran.}

Untuk dapat meningkatkan derajat kesehatan masyarakat khususnya yang berkaitan dengan metode pengobatan tradisional yang ada di Bali perlu dikaji secara lebih mendalam lagi agar metoda terapi yang kita miliki yang dikenal dengan usadha bukanlah pengetahuan usang yang tiada bermanfaat, sehingga dapat dijelaskan lebih ilmiah lagi dan dapat dijadikan sebagai sebuah solusi menjaga kesehatan, apalagi kita memiliki kekayaan alam yang luar biasa. Berkenaan dengan itu maka keberadaan pengetahuan dan alam Baliperlu dijaga keberadaannya agartetap memberi manfaat bagi kehidupan.

\section{DAFTAR PUSTAKA}

Anonim,2012.https://lusilamz123.wordpress.c om/2012/04/08/makalah-ayurveda/

Babu, S. Suresh, 2010.The Principles and Practice Of Kaya Cikitsa (Ayurveda'sInternal

Medicine).Varanasi.: Charu Printer

Dash, Vaidya Bhagawan \& Ramaswamy, Suhasini, 2006.Ayurveda. Surabaya. Pāramita

Mahadevan, L. 2012. Ayurveda For Beginners. Chennai: Mani Offset

Muray, Angela Hope \& Pickup, Tony. 1998. Penyembuhan Dengan Ayurveda. Jakarta. PT Gramedia Pustaka Utama.

Murthy, K. R. Srikantha. 2010. Illustrated Suśruta Samhitā. Varanasi: Charu Printers

Nala, Ngurah. 1992. Usada Bali. Denpasar: PT. Upada Sastra.

2001. Ayurveda Ilmu Kedokteran Hindu I. Denpasar: Upada Sastra

Rhyner, Hans H. 1998. AYURVEDA The Gentle Health System. Delhi: Shri Jainendra Press. 